\title{
FATIGUE STRENGTH OF NODULAR CAST IRON WITH DIFFERENT SURFACE CONDITIONS UNDER BENDING LOADING
}

The aim of this study is to evaluate the effects of surface conditions on the fatigue life of nodular cast iron under cyclic plane bending where the maximum stress is reached at the surface of interest. In order to evaluate the effect of surface conditions, fatigue tests were carried out on five sets of specimens with different surfaces. The surface conditions were as-cast, sand blasted, fine ground, nitrided and carbonitrided. The results show differences in fatigue strength, which are associated with the surface conditions. The characteristics of the surface layers in the different test specimens were examined by metallography. The fracture surfaces were fractographically analyzed to find places of fatigue crack initiation and to explain different fatigue life.

Keywords: Nodular cast iron, fatigue, defects, surface layers, plane bending

\section{Introduction}

Nodular cast irons (NCI) are technologically important materials and are used extensively in automotive industry. Defects produced during casting process often play a dominant role in limiting mechanical properties and fatigue life under cyclic loading in cast alloy components [1]. Besides the microstructural aspects such as chemical composition, nodule count and graphite shape, casting defects such as small shrinkage voids, porosities or dross defects play a dominant role in determining fatigue life and fatigue limit of cast irons [2]. Such defects make cast irons susceptible to brittle fracture and play the role of microscopic stress concentrators to promote the processes of nucleation and growth of cracks. NCI has been tested in fatigue with the aim to analyze the role of cast defects on fatigue crack initiation and propagation [3-6]. Many approaches to fatigue resistance evaluation for defect containing materials consider that a crack initiation stage is negligible and therefore fatigue crack propagation composes the whole fatigue process [7, 8]. Casting defects are inherent in the foundry processes and can be found in different cast alloys: aluminum alloys [7, 8], various steels $[9,10]$ or cast irons [4] for instance. Size, type and population of encountered casting defects depend on the alloy type and casting process [11]. Thermo-chemical surface treatments are frequently adopted with ferrous materials because they promote the formation of a hard and strong surface layer and of a system of compressive residual stress. Therefore, treatments, such as nitriding, simultaneously improve the fatigue endurance and the wear resistance $[12,13]$.

This paper presents and discusses the influence of surface conditions on fatigue behavior of pearlite/ferrite NCI. The dependence of the fatigue behavior on a specific surface condition is high- lighted using prismatic specimens tested under cyclic plane bending with maximum stress reached at the surface of interest. The characteristics of the surface layers in the different test specimens are examined by metallography. The fracture surfaces were studied under inspection of SEM to explain the differences in fatigue lives.

\section{Experimental material and methods}

The experimental material was prepared as synthetic melt from $2000 \mathrm{~kg}$ of pig iron, $300 \mathrm{~kg}$ of steel scrap, and $1500 \mathrm{~kg}$ of cast iron scrap. The melting was performed using an arched alkaline furnace with basic lining and $35 \mathrm{~kg}$ of FeSi was added to the melted metal as an additive to increase the content of $\mathrm{Si},[14,15]$. Chemical composition of the pearlite/ferrite NCI is given in Tab. 1. The cast material was supplied in the form of $140 \times 100 \times 20 \mathrm{~mm}$ plates.

Chemical composition of pearlite/ferritic NCI (in wt. \%) Tab. 1

\begin{tabular}{|c|c|c|c|c|c|c|c|c|}
\hline $\mathrm{C}$ & $\mathrm{Si}$ & $\mathrm{Mn}$ & $\mathrm{S}$ & $\mathrm{P}$ & $\mathrm{Mg}$ & $\mathrm{Cr}$ & $\mathrm{Cu}$ & $\mathrm{Ni}$ \\
\hline 3.68 & 2.62 & 0.51 & 0.005 & 0.05 & 0.034 & 0.2 & 0.02 & 0.01 \\
\hline
\end{tabular}

No annealing treatment was performed before machining the specimens used for tensile and fatigue testing. The tensile tests performed according to the ASTM E8 standard of the present NCI gave a tensile strength $R_{m}=576 \mathrm{MPa}$ and an elongation to the rupture $A=6 \%$. The fatigue specimen geometry, see Fig. 1, were prepared by machining cast plates. The role of different surface

\footnotetext{
* Marian Kokavec ${ }^{1}$, Radomila Konecna ${ }^{1}$, Gianni Nicoletto ${ }^{2}$

${ }^{1}$ Department of Materials Engineering, Faculty of Mechanical Engineering, University of Zilina, Slovakia, E-mail: marian.kokavec@fstroj.uniza.sk

${ }^{2}$ Department of Industrial Engineering, University of Parma, Italy
} 
conditions was investigated. Therefore, a set of specimens was obtained with an as-cast surface condition, Fig. 2, (the opposite face was in all cases fine ground). A second set of specimens had the as cast test surface sand blasted, Fig. 2, by compressed air pressure (i.e. $1 \mathrm{MPa}$ ) and a $\mathrm{SiC}$ sand abrasive (i.e. grain size 250-300 $\mu \mathrm{m}$ ). A third set of specimens had the test surface fine ground, Fig. 2, with a smooth finish achieved by removing the casting surface layers on a vertical milling machine and finishing by soft grinding on a disk sander. The final soft grinding was conducted by ceramic aluminum oxide wheel under the conditions of the grinding speed of $30 \mathrm{~m} / \mathrm{s}$, down feed $0.020 \mathrm{~mm} /$ pass.

Other two specimen sets with fine ground surfaces were subjected to thermo-chemical treatment, either nitriding or carbonitriding, to investigate the role of surface hardening on the fatigue behavior.

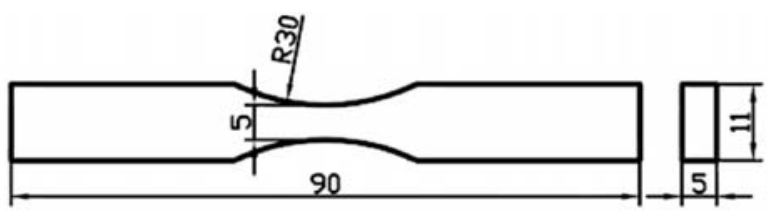

Fig. 1 Shape and dimensions of fatigue specimens

The structural analysis of NCI was performed on polished and etched specimens taken from cast plates. Structure details were analyzed in the light metallographic microscope according to the EN STN 420461 standard and by the methods of quantitative metallography [15]. Fig. 3 shows a typical microstructure of experimental material. The matrix was pearlite/ferritic with ferrite around the graphite nodules. Ferrite volume percentage of about $36 \%$ was calculated using image analysis obtained from low magnification images. The nodule count (the number of graphite particles per unit area of $\mathrm{mm}^{2}$ ) for studied nodular cast iron were in range $80-123$. The graphite nodules were observed in fully (VI) and partly not fully globular (V) shape. Size was predominately ranging from 30 to $60 \mu \mathrm{m}(6)$ and with a small number of nodules ranging in the size from 15 to $30 \mu \mathrm{m}(7)$.

The nitrided and carbonitrided layers were analyzed using methods of color etching because a high chemical heterogeneity characteristic for this region. Microhardness (HV 0.02) was measured on nitrided and carbonitrided specimens at different distances starting from the surface down to the core of material. The hardness profile characterizes the effectiveness of the nitriding treatment and is used to define an effective nitrided or carbonitrided depth.

Fatigue tests were performed on specimens using a fatigue test machine for cyclic plane bending with loading ratio $R=0$ and $25 \mathrm{~Hz}$ frequency. The tests were interrupted at $2.10^{6}$ cycles if the specimen did not fail. The ratio $R=0$ allowed to apply a cyclic tensile loading (the most critical in fatigue) to the surface of inter-

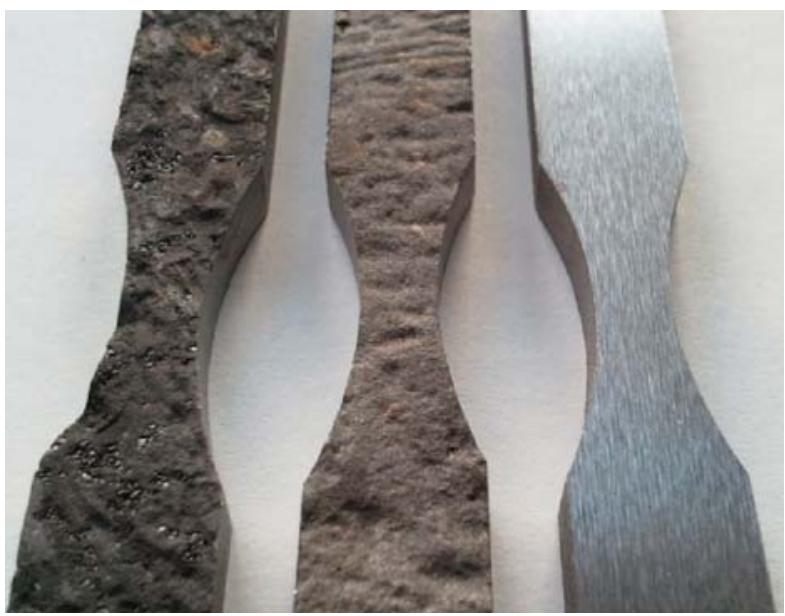

Fig. 2 Surface condition of specimens (from left as-cast, sand blasted, fine ground)

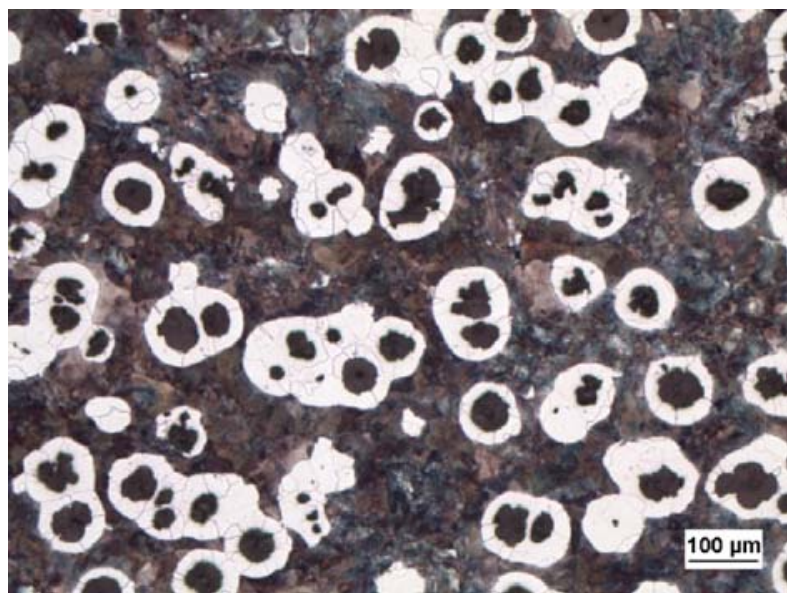

Fig. 3 Characteristic microstructure of experimental nodular cast iron, etched with 3\% Nital

est, either as-cast, sand blasted, fine ground, nitrided and carbonitrided. The initial stress range was associated to a fixed displacement range. A load-cell monitoring the specimen stress during the test allowed the determination of the evolution of specimen compliance. It was observed that the fixed initial stress range remained constant for a substantial part of the test followed by a continuous stress reduction in the final part because of fatigue crack initiation and propagation.

\section{Results and discussion}

The results of fatigue tests for all specimens are presented in Fig. 4. Trends of the $\mathrm{S} / \mathrm{N}$ dependence for different surface conditions were identified. A ranking of the five surface conditions in fatigue is experimentally obtained with the best performance associated to the thermo-chemical surface treatment. At $10^{6}$ cycles, 
the fatigue strength shows a decrease of approx. $20 \%$ going from a fine ground to a sand blasted surface and of approx. $30 \%$ going from nitrided or carbonitrided to a fine ground surface.

The scatter of results for specimens with as-cast surface was very large and estimation of the fatigue limit of these specimens from the trend of $\mathrm{S} / \mathrm{N}$ dependence was difficult. The large scatter of results can be explained by the presence of many defects in the cast surface layer, from which the fatigue cracks can initiate very quickly [16]. The specimens with as-cast and sand blasted surfaces showed very similar response in fatigue behavior. The thermochemical surface treatments showed the best fatigue behavior compared to the non-treated materials. Nitrided and carbonitrided $\mathrm{NCI}$ specimens showed quite similar fatigue behavior.

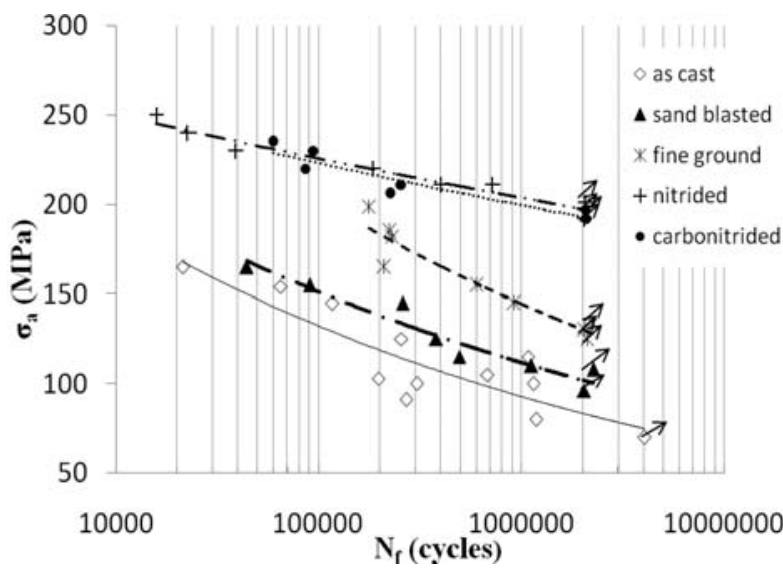

Fig. 4 S/N fatigue data after cyclic plane bending

Fatigue life of castings strongly depends on the surface condition. Only a few studies, [1, 4, 5, 17, 18], have been conducted on NCI castings with as-cast surfaces. In the presented case fatigue fracture initiation in as-cast and sand blasted specimens was observed with a scanning electron microscope (SEM) and these defects were found as fatigue crack initiation places (Fig. 6). However, the surface condition is expected to influence the fatigue crack initiation considerably with a strong effect associated to high surface roughness or by surface defects.

The surface and subsurface characteristics were metallographically investigated on cross sections perpendicular to the fracture surface and are discussed with reference to Fig. 5. Typically, the as-cast surface (Fig. 5a) is covered by a thin cast layer containing pores and cavities which negatively affect fatigue crack initiation. Just below this surface layer, a pearlitic layer with variable thickness, formed due to rapid solidification and cooling rate was found. Below these two layers and for the rest of the cross-section, the base NCI structure was found, see Fig. 3. The thickness of cast layer was approx. $36 \mu \mathrm{m}$ and pearlitic layer was variable in the range from 80 to $110 \mu \mathrm{m}$. The sand blasting treatment removes the thin cast layer of oxides and pores and locally deforms the metal but cannot remove pearlitic layer. Fig. $5 \mathrm{~b}$ shows that in the sand blast specimens the pearlite layer contains lamellar graphite, which gradually turns into vermicular and finally nodular shape going from the surface to the core of material. The combination of lower strength of pearlite matrix because of the presence of the lamellar graphite is expected to negatively affect the surface layer strength in case of fatigue loading because it results in early crack initiation compared to the presence of nodular graphite. Only fine grinding reduced significantly the surface roughness (i.e. by one order of magnitude) by complete elimination of the surface layers (formed by a thin cast layer of oxides and pores and layers with different structure than the core of material). The typical surface structure is shown in Fig. 3. The average surface roughness of fine ground specimens was $R a=2.3 \mu \mathrm{m}$.

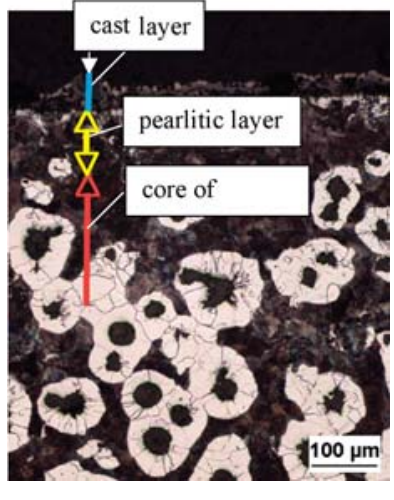

a)

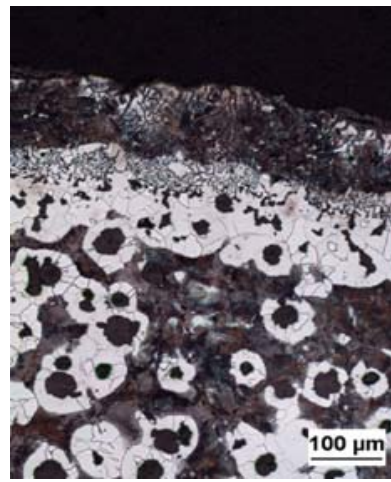

b)
Fig. 5 Typical structures of a) as-cast layer surface, b) sand blasted surface, etched 3\% Nital

The investigation of the thermo-chemically treated NCI specimens showed that both nitriding and carbonitriding produced layers formed by a thin white layer (WL) on the specimen surface and diffused zone (DZ) below, Fig. 7. The white layer was continuous with thickness about $21 \mu \mathrm{m}$ for nitrided surface and about $15 \mu \mathrm{m}$ for carbonitrided surface and with the local presence of graphite nodules in both cases. Thicker nitrided and carbonitrided layer and diffused zone were identified in areas where graphite particles presence was observed and WL was found below the graphite nodules.

Vickers microhardness profiles of the nitrided or carbonitrided layers are presented in Fig. 8. The hardness decreases with distance from the surface, following the decreasing nitrogen diffusion in the diffused zone to the basic material. Fig. 8 shows that the trend of the hardness measurements on the cross sections of the two types thermo-chemical treated specimens is similar. The highest value of HV $0.02=978$ was found in the white layer of nitrided specimens and HV $0.02=1088$ in the white layer of carbonitrided specimens. The values of microhardness decreases with increasing distance from surface and $348 \mathrm{HV} 0.02$ is hardness of pearlite in core region. 

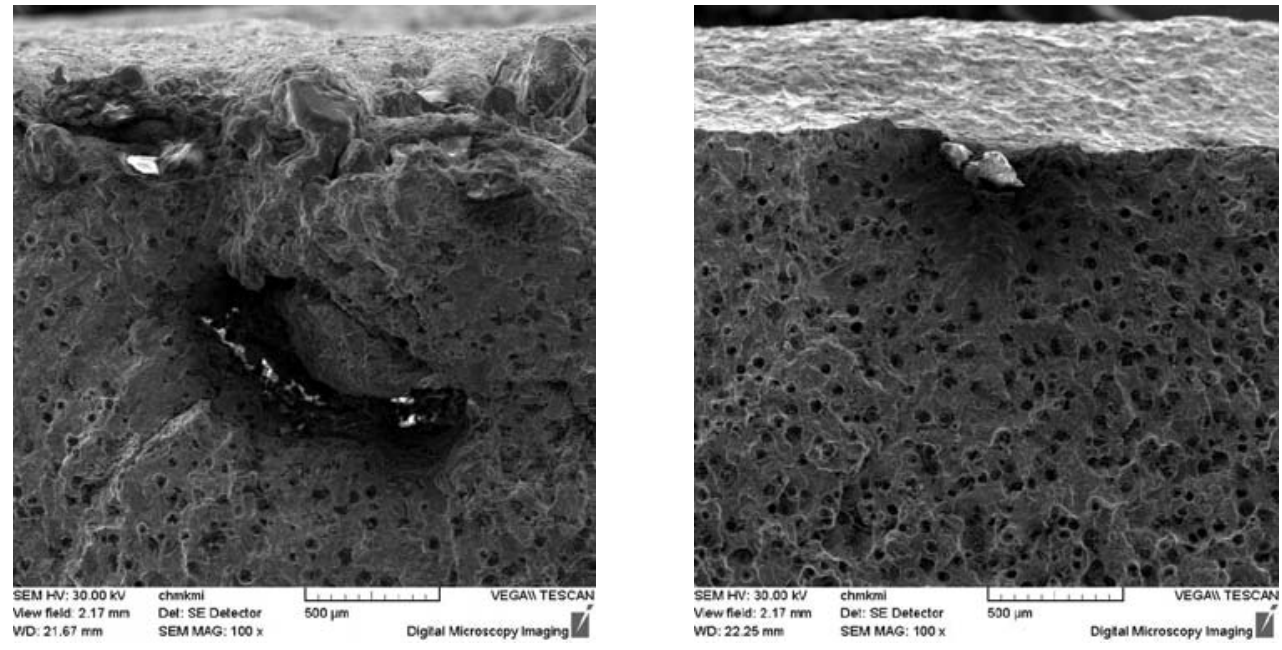

a) lustrous carbon film

b) slag

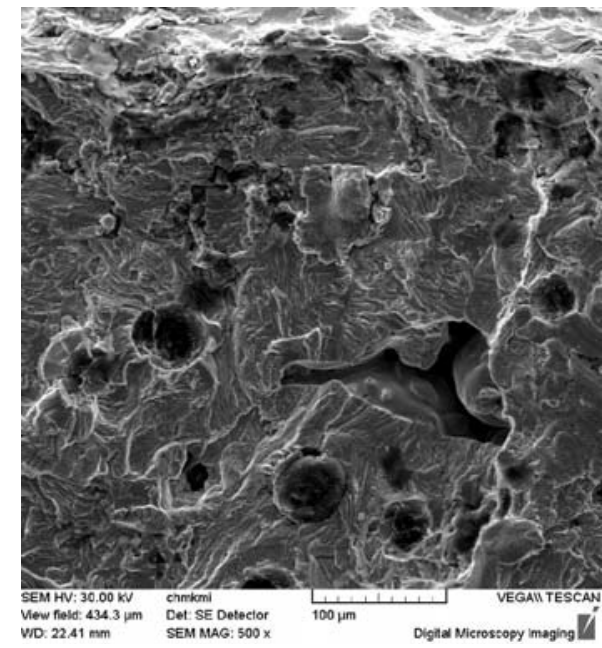

c) shrinkage

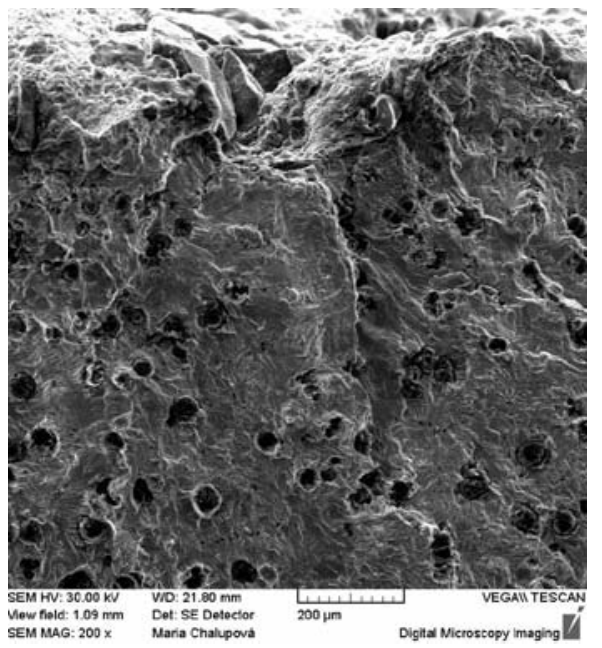

d) casting sand

Fig. 6 Fatigue crack initiation places in as-cast and sand blasted specimens, SEM

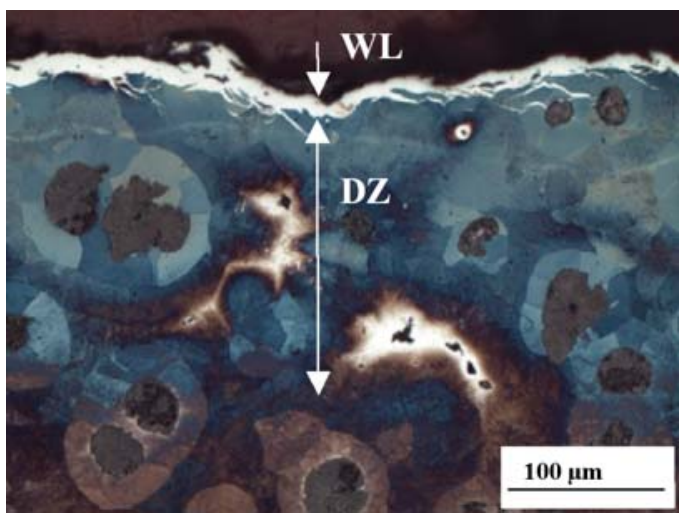

a)

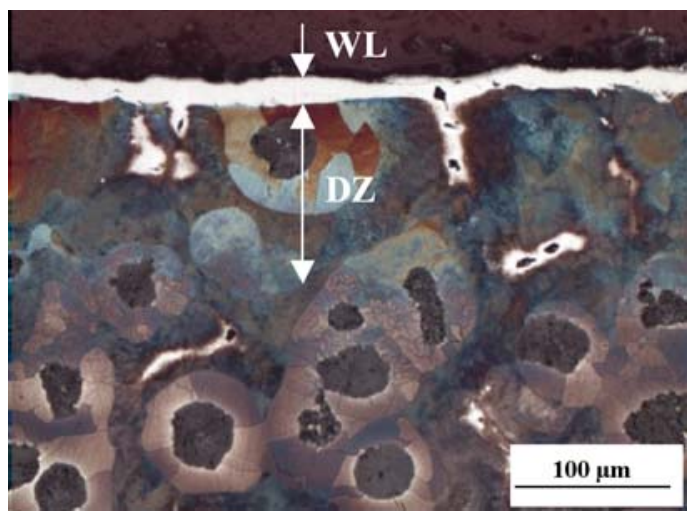

b)

Fig. 7 Structure of a) nitrided layer, b) carbonitrided layer, etched with Klemm II 


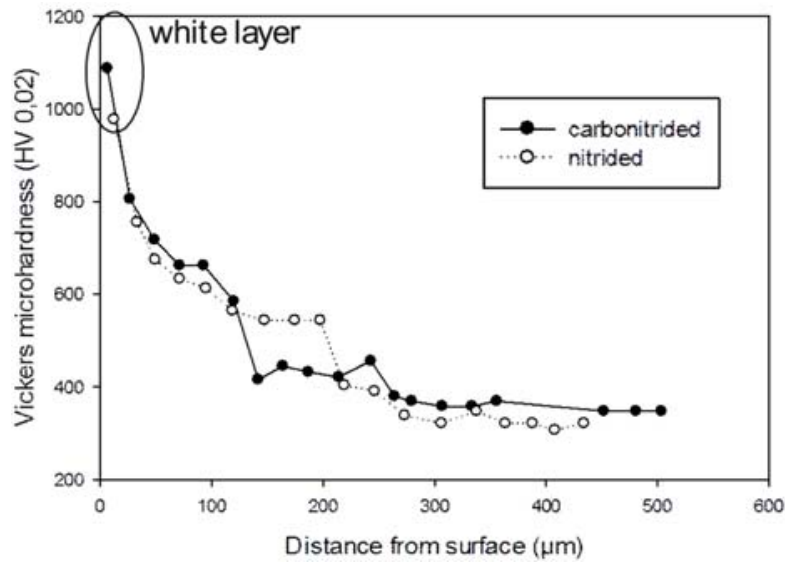

Fig. 8 Vickers microhardness measurements across the surface hardened layer

\section{Conclusions}

The surface characteristics of five different pearlite/ferritic NCI specimen sets and their fatigue behavior were investigated. From this study, the following conclusions can be drawn:

- The as-cast and sand blast surface condition produce similar and low fatigue strength of NCI specimens ( $70 \mathrm{MPa}$ at $4.10^{6}$ cycles for as-cast surface and $90 \mathrm{MPa}$ at $2.10^{6}$ cycles for sand blast surface) compared to the fine ground surface condition. Fine grinding of the $\mathrm{NCI}$ increases the fatigue strength of roughly $100 \%$ (134 MPa at $2.10^{6}$ cycles).

- Thermo-chemical treatment of smooth NCI specimens increases further the fatigue strength because of the hardened surface layer and the residual stress system. Carbonitriding and nitriding treatments achieve similar and considerable fatigue strength improvements (i.e. $50 \%$ ) compared to the untreated case (196,5 MPa at $2.10^{6}$ cycles for carbonitrided surface and $201 \mathrm{MPa}$ at $2.10^{6}$ cycles for nitrided surface).

- Fatigue fracture origins of nodular cast iron with as-cast and sand blasted surface are largely attributed to the surface roughness and defects existing in the vicinity of the surface and sub-surface. The as-cast surface layers are characterized by the presence of many defects and a brittle surface structure due to the presence of lamellar graphite, which is very different from the base pearlite/ ferritic metal microstructure with nodular graphite.

\section{Acknowledgements}

The research was supported by project VEGA grant No. $1 / 0196 / 12$.

\section{References}

[1] CHAKHERLOU, T. N., MAHDINIA, Y.V., AKBARI, A.: Influence of Lustrous Carbon Defects on the Fatigue Life of Ductile Iron Castings Using Lost Foam Process. Materials and Design, 2011, vol. 32, pp. 162-169.

[2] MURAKAMI, Y.: Metal Fatigue: Effect of Small Defects and Non-Metallic Inclusions. Elsevier, 2002.

[3] YAACOUB AGHA, H., BERANGER, A. S., BILLARDON, R., HILD, F.: High-Cycle Fatigue Behavior of Spheroidal Graphite Cast Iron. Fatigue Fracture of Eng. Materials Structures, 1998, vol. 21(3), pp. 287-296.

[4] NADOT, Y., MENDEZ, J., RANGANATHAN, N., BERANGER, A. S.: Fatigue Life Assessment of Nodular Cast Iron Containing Casting Defects. Fatigue Fracture of Eng. Materials Structures, 1999, vol. 22, pp. 289-300.

[5] YAMABE, J., KOBAYASHI, M.: Influence of Casting Durfaces on Fatigue Strength of Ductile Cast Iron. Fatigue Fracture of Eng. Materials Structures, 2006, vol. 29, pp. 403-415.

[6] CHANTIER, I., BOBET V., BILlARDON, R., HILDA, F.: A Probabilistic Approach to Predict the very High-Cycle Fatigue Behavior of Apheroidal Graphite Cast Iron Structures. Fatigue Fracture of Eng. Materials Structures, 2000, vol. 23, pp. 173-180.

[7] TING, J. C., LAWRENCE JR., F. V.: Modeling the Long Life Fatigue Behavior of a Cast Aluminum Alloy. Fatiguel Fractures of Eng. Materials Structures, 1993, vol. 16(6), pp. 631-47.

[8] GRANDT, A. F., SCHEUMANN, T. D., TODD, R. E., HINKLE, A. J.: Modeling the Influence of Initial Material Inhomogeneities on the Fatigue Life of Notched Components. Fatigue Fractures of Engineering Materials Structures, 1993, vol. 16(2), pp. 199-213.

[9] JAYET-GENDROT, S., GILLES, P., MIGNE, C.: Behavior of Duplex Stainless Casting Sdefects under Mechanical Loadings. Nuclear Engineering and Design, 2000, vol. 197 (1-2), pp. 141-153.

[10] HEUlER, P., BERGER, C., MOTZ, J.: Fatigue Behavior of Steel Castings Containing Nearsurface defects. Fatigue Fractures of Engineering Materials Structures, 1992, vol. 16(1), pp. 115-36.

[11] NADOT, Y., DENIER. V.: Fatigue Failure of Suspension Arm: Experimental Analysis and Multiaxial Criterion. Engineering Failure Analysis, 2004, vol. 11(4), pp. 485-499.

[12] DAVIS, J.: Cast Irons/Metallurgy and Properties of Ductile Cast Irons. ASM Specialty Handbook, The Materials Information Society, USA 1996.

[13] NICOLETTO G., TUCCI, A., ESPOSITO, L.: Sliding Ear Behavior of nitrided and nitrocarburized cast irons. Wear, vol. 197, 1996, p.38-44.

[14] KOKAVEC, M., KONECNA, R., NICOLETTO G.: Influence of Surface Quality on Fatigue Behavior of Nodular Cast Iron. Acta Metallurgica Slovaca, 2011, No. 2, pp. 99-105. 
[15] KONECNA, R., ZAHOROVA, B., MATEJKA, M.: Vplyv prisady SiC na porusovanie tvarnej liatiny [Influence of SiC Additives on Fracture of Nodular Cast Iron]. Materialove inzinierstvo 7 (4), 2000, p. 27-34.

[16] KUNZ, L.: Experimentalni stanoveni unavovych charakteristik materialu [Experimental Determination of Fatigue Characteristics of Materials], EDIS, Zilina, 2003 (in Czech).

[17] COSTA, N., MACHADO, N., SILVA, F. S.: A New Method of Prediction of Nodular Cast Iron Fatigue Limit. Intern. J. of Fatigue, 2010, vol. 32 (7), pp. 988-995.

[18] COLLINI, L., PIRONDI, A., BIANCHI, R., COVA, M., MILELLA, P. P.: Influence of Casting Defect on Fatigue Crack Initiation and Fatigue Limit of Ductile Cast Iron. Procedia Engineering, 2011, vol. 10, pp. 2898-2903. 